\title{
The Behavioral Model development of pregnant women in accordance to pregnancy treatment lifestyle
}

\author{
Evi Pratami ${ }^{\text {a }}$, Sukesi Sukesi ${ }^{\text {a, }}$ Ervi Husni ${ }^{\text {a }}$, Nursalam Nursalam ${ }^{\text {b, }}$ \\ ${ }^{\text {a }}$ Health Poytechnic of Surabaya, Surabaya, Indonesia \\ ${ }^{\mathrm{b}}$ Faculty of Nursing, Universitas Airlangga, Surabaya, Indonesia
}

\section{A R T I C L E I N F O}

\section{Keywords:}

Lifestyle

Behavior

Pregnancy

Model

\begin{abstract}
A B S T R A C T
Background: Maternal morbidity has shifted from malnutrition to metabolic disease. Lifestyle patterns have great influence on an individual's behavior. Therefore, an unhealthy lifestyle would create a poor quality life prone to life threatening diseases.

Objective: This study aimed to analyze the model behavior of pregnant women based on pregnancy treatment lifestyle.

Method: A mixed methods explanatory research with 2 stage, cross sectional and auasy experimental design. This first study conducted in 256 respondents that gathering used ROT formula. Furthermore, the sampling technique used is non probability sampling, whereas the data analysis used SEM-PLS. The second study was conducted by using an experimental observational. Sixty respondents as sample were selected using non probability sampling. Data was analyzed using the Wilcoxon test and Mann Whitney.

The results: The first stage of the study presents that activities, interests, and opinions influence the regularity of antenatal care with T statistic 2014; 3734 and 2,433, respectively. Moreover, activity and interest influence the accuracy of drugs or vitamins consumption (T statistic 2485 and 2950). While opinions do not affect the accuracy of drugs or vitamins consumption ( $\mathrm{T}$ statistic 2433), however, activities and opinions affect diet ( $\mathrm{T}=4164$; 3312). Furthermore, interests do not affect eating patterns $(\mathrm{T}=0.864)$, but activities, interests and opinions influence Monitoring fetal movements $(\mathrm{T}=2183 ; 2325 ; 2222)$. In addition, interest affects activity patterns in pregnant women $(\mathrm{T}=2,048)$. The second stage showed that all variable in intervention group have difference result than control group $(\mathrm{P}<0,05)$.

Conclusion: A lifestyle model of behavior can improve the behavior of pregnant women in caring for their pregnancy.
\end{abstract}

\section{Introduction}

In recent decades, many studies have discovered that lifestyle is an important factor in an individual's health. ${ }^{1}$ Pregnant women with a poor lifestyle will cause various health problems, including large pregnancies, gestational diabetes mellitus, cardiovascular disorders, risky pregnancies and many other things, these conditions will also have an impact on the condition of the fetus in the mother's body and various comorbidities. an emergency. ${ }^{2,4,7}$ According to the World Health Organization (WHO), 60\% of lifestyle factors are related to quality of life. An individual's lifestyle is related to problems such as metabolic diseases, joint and bone problems, cardiovascular problems, hypertension, excess weight, violence and so on. Therefore, lifestyle and health should be considered as priority ${ }^{2}$ Other studies have also identified a lifestyle that will both prolong life expectancy and keep diseases away. ${ }^{3}$ Moreover, Bourdieu also revealed that in a lifestyle there are interactions that show the identity of the individuals. What is attached to the individual shows the lifestyle that he follows. The capital they have can create the lifestyle they desire. However, this desire is also influenced by the media. Furthermore, social status is not defined by a person's position in a group or social class, but it is created from what they assume, for instance, differences in lifestyle desires, choices regarding how to dress, how to fill spare time, and taste in music give a sign about someone's social status and position. These also used as a tool to maintain the

\footnotetext{
* Corresponding author. Department of Fundamendal, Medical Surgical and Critical Nursing, Faculty of Nursing, Campus C Universitas Airlangga, Surabaya, 60115, Indonesia.

E-mail address: nursalam@fkp.unair.ac.id (N. Nursalam).
} 
existing social structure ${ }^{4}$

Behavior is forming the personality of each individual and determines the attitude in making decisions. Good behavior will determine the success of a program that has been planned. The degree of health is said to be successful if the behavior shows a change in a positive direction, on the contrary, if the behavior does not show changes and gets worse, it is necessary to evaluate the program that has been planned. ${ }^{5,6}$

So far, the behavior change model has not shown significant results, it is necessary to develop models continuously to continue to improve unsatisfactory behavior. ${ }^{7,8}$ The existing behavior models show many types of changes that exist, but have not shown perfect results, especially in the behavior of pregnant women. ${ }^{9}$ Pregnant women with lots of lifestyle changes that can have both positive and negative impacts. The thing that is of concern is if pregnant women show a negative impact, so it is necessary to make improvements to the behavior model so far. ${ }^{10,11}$

Moreover, this research aims to analyze the influence of lifestyle (activity factors, interests and opinions) on regularity of antenatal care, accuracy of drugs or vitamins consumption, diet, monitoring of fetal movements on pregnant women, activity patterns, and analyze the lifestyle models that affect on the improvement of pregnant women behavior.

\section{Methods}

This particular research is conducted in 2 stages, the first stage was cross sectional design and the second was quasy experimental study, between two stage there was conducted focus group discussion (FGD) and expert consultation. The first stage of the research uses cross sectional approach towards the population of pregnant women in Surabaya City Health Office. The samples used are several pregnant women who met the inclusion and exclusion criteria. The inclusion criteria in this study includes: 1) pregnant women who have a medical check up health booklet for pregnant women and complete records; 2) have made at least 2 antenatal visits; 3) Pregnant women in first pregnancy trimester; and 4) They are willing to become respondents by signing the respondent's consent form. The exclusion criteria were: 1) Pregnant women with comorbid and other diseases; 2) Have psychological and mental health disorder; and 3) Not cooperate.

The number of samples of this particular study were 256 respondents, which is obtained from the rule of the thumb size, 5 times the amount of indicators in the study. The author used the rule of thumb because this sample is the best choice for model development. Besides, the sampling technique used is non probability sampling, it was purposive sampling. In addition, the independent variable in this particular research was lifestyle (behavior, opinion and interest) whereas the dependent variable was the behavior of pregnant women at high risk. Data collection used modified questionnaire with validity and reliability test before, the result was valid and reliable. Researcher conducted data collection using online system with google form and also offline by 4 cadres in direct practice. Cadre was coordinated by researcher before collect the data, researcher gave them knowledge and trial until them can doing well. Furthermore, after data tabulated, the variables were analyzed using Partial Least Square (PLS) method to determine the inner and outer model, loading factors, good of fitness, T statistics and hypothesis test.

Then, the next step was determined strategic issue for a $F G D$ that involves 20 participants. The issue strategic was consultation about the content of the module before using as a tool of data collection. FGD conducted to discuss the strategic issue and made recommendation to next step of the research. Expert consultation conducted after FGD and the purpose was improved the modul for intervention in second stage, expert consultation conducted with the maternity nursing expert and behavior expert. Furthermore, stage 2 uses a quasi-experimental design, in which the sample size for this study was 60 respondents. The intervention group was given modul treatment and the control group given intervention as a usual. Treatment that given to respondent was given the modul in one month, they follow the instruction from the modul to maintenance the condition, vital sign, antenatal care, risk of pregnancy and also therapy for pregnant women in the modul. Data collected in pre and post test using questionnaire for behavior of pregnant women at high risk. The instrument was tested with validity and reliability before, the result was valid (all $\mathrm{r}$ results higher than 0.214) and reliable (Cronbach alpha 0.678-0.899). Then the data was analyzed by using the Wilcoxon and Mann Whitney test. This study was approval by Ethical Clearance from Health Polytechnic of Surabaya.

\section{Results}

Table 1 showed the convergent validity results, that which presents the results of convergent validity for the research latent variables, it was found that all variables have a loading factor value $>0.6$ and the results of $t$ count can be said to be valid if the value is more than 1.96 so that from the results of table all indicators pass the convergent validity test. The convergent results of the construct validity for the research variables showed that it is found that all variables have an AVE value $>0.5$ so that they pass the construct validity test (Table 2). The reliability and Cronbach's Alpha for each variable is $>0.70$ in other words, the variable is consistent in this measurement, thus it is concluded that the variables used in this study have met the reliability test (Table 3).

It was known that the value of the $t$-test results for each exogenous to

Table 1

Convergent validity test results.

\begin{tabular}{|c|c|c|c|c|c|}
\hline $\begin{array}{l}\text { Latent } \\
\text { Variable }\end{array}$ & Dimensions & Indicator & $\begin{array}{l}\text { Loading } \\
\text { factor }\end{array}$ & $\begin{array}{l}\mathrm{T} \\
\text { Statistcs }\end{array}$ & Remarks \\
\hline \multirow{34}{*}{ Lifestyle } & $\mathrm{X} 1$. & X1.1 Job & 0.689 & 15.814 & Valid \\
\hline & \multirow[t]{11}{*}{ Activity } & X1.2 Hobby & 0.734 & 16.659 & Valid \\
\hline & & X1.3 Social & 0.738 & 16.455 & Valid \\
\hline & & Activities & & & \\
\hline & & X1.4 Holiday & 0.717 & 15.079 & Valid \\
\hline & & $\mathrm{X} 1.5$ & 0.692 & 12.761 & Valid \\
\hline & & Entertainment & & & \\
\hline & & $\begin{array}{l}\text { X1.6 Club } \\
\text { Membership }\end{array}$ & 0.625 & 10.941 & Valid \\
\hline & & $\mathrm{X} 1.7$ & 0.711 & 17.241 & Valid \\
\hline & & Community & & & \\
\hline & & X1.8 Shopping & 0.928 & 72.860 & Valid \\
\hline & & X1.9 Sports & 0.672 & 14.267 & Valid \\
\hline & \multirow[t]{13}{*}{ X2. Interest } & X2.1 Family & 0.719 & 17.943 & Valid \\
\hline & & X2.2 House & 0.668 & 13.243 & Valid \\
\hline & & $\mathrm{X} 2.3$ & 0.692 & 15.324 & Valid \\
\hline & & Occupation & & & \\
\hline & & $\mathrm{X} 2.4$ & 0.746 & 13.870 & Valid \\
\hline & & Communities & & & \\
\hline & & $\mathrm{X} 2.5$ & 0.661 & 9.399 & Valid \\
\hline & & Recreation & & & \\
\hline & & X2.6 Mode & 0.713 & 12.467 & Valid \\
\hline & & X2.7 Food & 0.708 & 11.552 & Valid \\
\hline & & X2.8 Media & 0.706 & 16.025 & Valid \\
\hline & & $\mathrm{X} 2.9$ & 0.756 & 14.967 & Valid \\
\hline & & Achievement & & & \\
\hline & \multirow[t]{9}{*}{ X3 Opinion } & X3.1 Self & 0.707 & 13.593 & Valid \\
\hline & & $\begin{array}{l}\text { X3.2 Social } \\
\text { Problem }\end{array}$ & 0.799 & 17.103 & Valid \\
\hline & & X3.3 Politics & 0.745 & 18.510 & Valid \\
\hline & & X3.4 Business & 0.753 & 17.501 & Valid \\
\hline & & X3.5 Economy & 0.650 & 15.342 & Valid \\
\hline & & X3.6 Education & 0.731 & 13.902 & Valid \\
\hline & & X3.7 Products & 0.687 & 11.830 & Valid \\
\hline & & X3.8 Future & 0.679 & 10.084 & Valid \\
\hline & & X3.9 Culture & 0.670 & 12.085 & Valid \\
\hline \multirow{6}{*}{$\begin{array}{l}\text { Behavior of } \\
\text { Women } \\
\text { in } \\
\text { Pregnant }\end{array}$} & \multicolumn{2}{|c|}{ Y1 Regularity of Pregnancy } & 1.000 & & Valid \\
\hline & \multicolumn{2}{|c|}{ Y2 The Accuracy of Taking } & 1.000 & & Valid \\
\hline & \multicolumn{2}{|c|}{ Y3 Diet for Women in Pregnant } & 1.000 & & Valid \\
\hline & \multicolumn{2}{|c|}{ Y4 Fetal Movement } & 1.000 & & Valid \\
\hline & \multicolumn{2}{|l|}{ Monitoring } & & & \\
\hline & \multicolumn{2}{|c|}{ Y5 Activity Patterns } & 1.000 & & Valid \\
\hline
\end{tabular}


Table 2

Construct validity test results.

\begin{tabular}{lll}
\hline Variable & AVE Value & Remarks \\
\hline X1.1. Activity & 0.529 & Valid \\
X1.2 Interest & 0.502 & Valid \\
X1.3 Opinion & 0.511 & Valid \\
Y1 Regular Pregnancy Examination & 1.000 & Valid \\
Y2 The Accuracy of Taking Drugs/Vitamins & 1.000 & Valid \\
Y3 Diet for Women in Pregnant & 1.000 & Valid \\
Y4 Fetal Movement Monitoring & 1.000 & Valid \\
Y5 Activity Patterns & 1.000 & Valid \\
\hline
\end{tabular}

Table 3

Construct reliability test results.

\begin{tabular}{lll}
\hline Variable & $\begin{array}{l}\text { Cronbach's } \\
\text { Alpha }\end{array}$ & $\begin{array}{l}\text { Composite } \\
\text { Reliability }\end{array}$ \\
\hline X1.1. Activity & 0.887 & 0.909 \\
X1.2 Interest & 0.879 & 0.900 \\
X1.3 Opinion & 0.880 & 0.904 \\
Y1 Regular Pregnancy Examination & 1.000 & 1.000 \\
Y2 The Accuracy of Taking Drugs/ & 1.000 & 1.000 \\
$\quad$ Vitamins & & \\
Y3 Diet for Pregnant Women & 1.000 & 1.000 \\
Y4 Fetal Movement Monitoring & 1.000 & 1.000 \\
Y5 Activity Patterns & 1.000 & 1.000 \\
\hline
\end{tabular}

endogenous latent variable with a value of $t>1.97$. The highest statistical value was the effect of activity to eat pattern with $\mathrm{T}$ statistic 4.649 and also interest to regularity examination with $\mathrm{T}$ statistics 3.982 (Table 4). The results of the pre and post tests statistical test using the Wilcoxon test show that for the control group the value of siq $>0.05$ in all variables which means there is no difference between pre and post in the control group. Whereas in the treatment group, the results of siq $<0.05$ on all variables, which means that there is a difference between pre and post in the treatment group (Table 5). Based on Table 6, it was found that after testing the differences in behavior of pregnant women in the control and treatment groups using Mann Whitney, it was found that the pre-treatment (before treatment) has a value of siq $>0.05$ in all variables which means there was no difference between the controls with treatment in the pre test. Whereas in the post group (after treatment) the results obtained siq $<0.05$ on all variables, which means there is a difference between control and treatment in the post test.

\section{Discussion}

Lifestyle is defined as the pattern in which people live and spend their time and money. Lifestyle can also be defined as a function of consumer motivation and previous learning, social class, demographics, and other variables. Lifestyle is a summary conception that reflects consumer value. Research conducted by Lin et al., in 2016 found that pregnant women may not immediately change unhealthy lifestyles in the first trimester. However, this may be associated with poor neonatal outcomes. Adopting an intervention program to encourage lifestyle modification in women who are planning to become pregnant or who have recently become pregnant is very important to prevent adverse neonatal outcomes. ${ }^{12}$

Furthermore, research conducted by Patsy et al., In 2017 suggests that the needs of pregnant women against iron must be fulfilled, since there are several conditions that can be caused from iron deficiency. On this basis, policy support is needed, so that it can be obeyed by all parties. ${ }^{13}$ Moreover, healthy weight and healthy lifestyle behaviors are considered essential prerequisites for a successful pregnancy. The importance of a mother's lifestyle including nutrition and physical activity in relation to short and long term birth outcomes is increasingly featured in much of the literature. ${ }^{14,15}$ Recently, more attention has been given to excessive pregnancy weight gain and obesity as this has been shown to significantly increase the risk of complications during pregnancy and obesity. Birth and increases the risk of obesity in offspring. ${ }^{16}$ Furthermore, Li Tang conducted research in China which has a less developed economy. Due to the dynamic nature of lifestyles, dietary habits and modern nutrition, limited knowledge and understanding about mother's lifestyle and nutritional status needs to be updated. ${ }^{17,18}$ This also applies to its impact on pregnancy and infants. Although breast milk is the preferred feeding option, the use of infant formula is vastly practiced in China. ${ }^{19}$

In addition, a research conducted by Asci and Rathfish concluded that lifestyle interventions improve lifestyle behavior during pregnancy and increase the corresponding GWG (Gestational Weight Gain) for body mass index (BMI) before pregnancy, but have a limited effect in terms of improving eating habits and not effect on PWR (Postpartum Weight Retention. ${ }^{20}$ This study is also supported by Lin et al. in a research conducted in 2016. They discovered that pregnant women may not immediately change unhealthy lifestyles in the first trimester; however, this may be associated with poor neonatal outcomes. Adopting an intervention program to encourage lifestyle modification in women who are planning to become pregnant or who have recently become pregnant is very important to prevent adverse neonatal outcomes. ${ }^{12}$

This study found that lifestyle (activity factors, interests and opinions) affects the regularity of antenatal care in pregnant women. However, the community tends to be good in the activity, request and opinion factors concerned about the regularity of pregnancy examinations, whether it is carried out at the Independent Practice Midwife, Puskesmas or other health services. ${ }^{6,21}$ The existence of good activities are supported by supportive interests. Besides, positive opinions can direct clients' actions to always check the condition of their pregnancy. This capital can be used as a basis so that early detection of pregnancy complications can be determined early. Therefore, that planning for the creation of quality generations can be executed optimally. ${ }^{22,23}$

Opinions are around the views and feelings of consumers in response to global, local, economic and social issues. Opinions are used to describe interpretations, expectations and evaluations, such as beliefs about the intentions of others, anticipation regarding future events and weighing the consequences that reward or punish the course of

Table 4

Inner model analysis and path coefficients in the initial structural model.

\begin{tabular}{|c|c|c|c|c|c|c|}
\hline & Original Sample (O) & Sample Mean (M) & Standard Deviation (STDEV) & T Statistics $(|\mathrm{O} / \mathrm{STDEV}|)$ & P Values & Remarks \\
\hline F.Activity - > Fetal Motion & -0.132 & -0.129 & 0.058 & 2.275 & 0.023 & Significant \\
\hline F.Activity - > Regularity. Medicine & 0.147 & 0.153 & 0.056 & 2.637 & 0.009 & Significant \\
\hline F.Activity - > Regularity. Check & -0.136 & -0.138 & 0.066 & 2.074 & 0.039 & Significant \\
\hline F.Activity - > Pattern. Eat & 0.215 & 0.223 & 0.046 & 4.649 & 0.000 & Significant \\
\hline F.Interest - > Fetal. Movement & 0.134 & 0.138 & 0.057 & 2.363 & 0.019 & Significant \\
\hline F.Interest - > Regularity. Medicine & 0.199 & 0.200 & 0.069 & 2.878 & 0.004 & Significant \\
\hline F.Interest - > Regularity. Examination & 0.211 & 0.217 & 0.053 & 3.982 & 0.000 & Significant \\
\hline F.Interest - > Patterns. Activities & 0.131 & 0.137 & 0.055 & 2.383 & 0.018 & Significant \\
\hline F.Opinion - > Fetal. Motion & 0.127 & 0.134 & 0.055 & 2.304 & 0.022 & Significant \\
\hline F.Opinion - > Regularity. Inspection & 0.154 & 0.159 & 0.063 & 2.460 & 0.014 & Significant \\
\hline F.Opinion - > Pattern. Meal & 0.174 & 0.182 & 0.047 & 3.714 & 0.000 & Significant \\
\hline
\end{tabular}


Table 5

Analysis of the behavior of pre and post pregnant women in the treatment and control groups.

\begin{tabular}{|c|c|c|c|c|c|c|c|c|}
\hline \multirow[t]{2}{*}{ Variable } & \multicolumn{2}{|l|}{ Treatment } & \multirow[t]{2}{*}{ Difference in Mean } & \multirow{2}{*}{$\begin{array}{l}\text { P- } \\
\text { Value }\end{array}$} & \multicolumn{2}{|l|}{ Control } & \multirow[t]{2}{*}{ Difference in Mean } & \multirow{2}{*}{$\begin{array}{l}\text { P- } \\
\text { Value }\end{array}$} \\
\hline & Pre Mean \pm SD & Post Mean \pm SD & & & Pre Mean \pm SD & Post Mean \pm SD & & \\
\hline Check for Pregnancy & $2.00 \pm 1.017$ & $3.23 \pm 0.430$ & 1.23 & 0.000 & $2.03 \pm 1.066$ & $2.07 \pm 0.980$ & 0.04 & 0.705 \\
\hline Consumption of Drugs \& Vitamins & $1.30 \pm 0.702$ & $3.30 \pm 0.466$ & 2.00 & 0.000 & $1.30 \pm 0.651$ & $1.47 \pm 0.819$ & 0.17 & 0.206 \\
\hline Dietary habit & $1.27 \pm 0.691$ & $3.37 \pm 0.490$ & 2.10 & 0.000 & $1.27 \pm 0.691$ & $1.43 \pm 0.774$ & 0.16 & 0.206 \\
\hline Fetal Motion Monitoring & $2.67 \pm 1.213$ & $3.57 \pm 0.504$ & 0.90 & 0.000 & $2.60 \pm 1.192$ & $2.57 \pm 1.135$ & -0.03 & 0.739 \\
\hline Activity Patterns & $2.43 \pm 0.898$ & $3.67 \pm 0.479$ & 1.24 & 0.000 & $2.40 \pm 1.037$ & $2.37 \pm 0.999$ & -0.03 & 0.739 \\
\hline
\end{tabular}

Note: using a different Wilcoxon Test if the P-Value $<0.05$.

Table 6

Analysis of differences in the behavior of pregnant women in the treatment and control groups.

\begin{tabular}{|c|c|c|c|c|c|c|c|c|}
\hline \multirow[t]{2}{*}{ Variable } & \multicolumn{2}{|l|}{ Pre } & \multirow{2}{*}{$\begin{array}{l}\text { Difference in } \\
\text { Mean }\end{array}$} & \multirow{2}{*}{$\begin{array}{l}\mathrm{P} \text { - } \\
\text { Value }\end{array}$} & \multicolumn{2}{|l|}{ Post } & \multirow{2}{*}{$\begin{array}{l}\text { Difference in } \\
\text { Mean }\end{array}$} & \multirow{2}{*}{$\begin{array}{l}\text { P- } \\
\text { Value }\end{array}$} \\
\hline & $\begin{array}{l}\text { Control Mean } \\
\pm \mathrm{SD}\end{array}$ & TreatmentMean \pm SD & & & $\begin{array}{l}\text { Control Mean } \\
\pm \mathrm{SD}\end{array}$ & TreatmentMean \pm SD & & \\
\hline Check for Pregnancy & $2.03 \pm 1.066$ & $2.00 \pm 1.017$ & 0.03 & 0.944 & $2.07 \pm 0.980$ & $3.23 \pm 0.430$ & 1.16 & 0.000 \\
\hline $\begin{array}{l}\text { Consumption of Drugs \& } \\
\text { Vitamins }\end{array}$ & $1.30 \pm 0.651$ & $1.30 \pm 0.702$ & 0.00 & 0.818 & $1.47 \pm 0.819$ & $3.30 \pm 0.466$ & 1.86 & 0.000 \\
\hline Dietary habit & $1.27 \pm 0.691$ & $1.27 \pm 0.691$ & 0.00 & 1.000 & $1.43 \pm 0.774$ & $3.37 \pm 0.490$ & 1.94 & 0.000 \\
\hline Fetal Motion Monitoring & $2.60 \pm 1.192$ & $2.67 \pm 1.213$ & 0.07 & 0.830 & $2.57 \pm 1.135$ & $3.57 \pm 0.504$ & 1.00 & 0.000 \\
\hline Activity Patterns & $2.40 \pm 1.037$ & $2.43 \pm 0.898$ & 0.03 & 0.865 & $2.37 \pm 0.999$ & $3.67 \pm 0.479$ & 1.30 & 0.000 \\
\hline
\end{tabular}

Uji Mann Whitney different if the P-Value $<0.05$.

alternative actions. ${ }^{24,25}$ If it is related to the respondent's behavior towards the regularity in drugs and vitamins consumption, it gives meaning that the respondent does not fully understand the importance of taking drugs or vitamins. Therefore, activities that have been formed are more than just consuming without being supported by a good opinion about the importance of taking medication or vitamins which have an important role in maintaining pregnancy.

Interest states what interests, likes, hobbies, and priorities in the consumer's life. If it is associated with the study, it can be inferred that the activities and opinions of respondents to maintain diets are not influenced by his interest. ${ }^{11,26}$ Thus, the role requested will have no effect on maternal behavior, especially in maintaining the diet of this research to get the results that lifestyle factors interest in influencing the pattern of activity in the pregnant mother. Whereas the activity and opinion factors do not affect the activity pattern of pregnant women. This gives meaning that the pattern of activities of pregnant women only stops in the interest stage, without being followed up with activities or interests.

The Behavioral Model embodied in this study can significantly increase social sensitivity, and indirectly increase community empowerment, increase shared responsibility, and increase social interaction in society. Pregnant women are no longer the responsibility of midwives and families, but they become social responsibilities, starting from midwives, health workers, cadres, and community leaders.

\section{Conclusion}

In conclusion, lifestyle (activity factors, interests and opinions) can influence the regularity of pregnancy examinations in pregnant women, lifestyle (activity factors, interests) can influence the accuracy of consuming drugs or vitamins in mothers pregnancy. Whereas opinion factors do not affect the accuracy of drugs or vitamins consumption in pregnant women. Moreover, lifestyle (activity factors, and opinions) are able to influence the diet of pregnant women, while the interest factor does not affect the accuracy of drugs or vitamins consumption in pregnant women. On the other hand, life (activity factors, interests and opinions) can have an influence on monitoring fetal movements in pregnant women, while lifestyle (activity factors and opinions) are able to influence activity patterns in pregnant women. In addition, interest factors do not affect the accuracy of drugs or vitamins consumption of pregnant women. Improving the behavior of pregnant women is developed an application of a lifestyle model (activities, interests and opinions).

\subsection{Suggestions}

In order to improve the lifestyle, especially with regard to maternal behavior in maintaining pregnancy, increasing community participation in supporting the formation of a positive lifestyle related to the behavior of pregnant women is highly suggestible. Besides that, optimizing the formation of clubs or associations for pregnant women, improving media and methods of delivering information, especially those related to improving behavior of pregnant mothers can also be considered.

\section{Acknowledgement}

The authors state thanks to pregnancy community in Surabaya for contributing as respondent in this research, we also thank to our institution, Health Poytechnic of Surabaya, for facilitate this research, so authors can finish the study. We also thank to all contribute people that give facilitate for this research. The highest thanks we give to Health Ministry of Indonesia that give funding for this research.

\section{References}

1 Stephenson J, Heslehurst N, Hall J, et al. Before the beginning: nutrition and lifestyle in the preconception period and its importance for future health. Lancet. 2018;391, $1830-41$.

2 Farhud DD. Impact of Lifestyle on Health. 2015;44(11):1442-1444.

3 Kaptoge S, Angelantonio E Di. Impact of Healthy Lifestyle Factors on Life Expectancies in the US Population. 2018:345-355.

4 Syakir. Seni Perbatikan Semarang: Tinjauan Analitik Prespektif Bourdieu pada Praksis Arena Produksi Kultural. 2016;X(2).

5 Evenson KR, Barakat R, Brown WJ, et al. Guidelines for physical activity during pregnancy: comparisons from around the World. Am J Lifestyle Med. 2014;8: $102-121$.

6 Brown J, Alwan NA, West J, et al. Lifestyle Interventions for the Treatment of Women with Gestational Diabetes, 2017. Cochrane Database of Systematic Reviews; 2017.

7 Rogozinska E, D'Amico MI, Khan KS, et al. Development of composite outcomes for individual patient data (IPD) meta-analysis on the effects of diet and lifestyle in pregnancy: a Delphi survey. BJOG An Int J Obstet Gynaecol. 2016;123, 190-8.

8 Kennelly MA, Ainscough K, Lindsay K, Gibney E, Mc Carthy M, McAuliffe FM. Pregnancy, exercise and nutrition research study with smart phone app support (Pears): study protocol of a randomized controlled trial. Contemp Clin Trials. 2016;46: 92-99. 
9 Jones I, Chandra PS, Dazzan P, Howard LM. Bipolar disorder, affective psychosis, and schizophrenia in pregnancy and the post-partum period. Lancet. 2014;384: 1789-1799.

10 Dencker A, Premberg $\AA$, Olander EK, et al. Adopting a healthy lifestyle when pregnant and obese - an interview study three years after childbirth. BMC Pregnancy Childbirth. 2016;16(1).

11 Gilbert L, Gross J, Lanzi S, Quansah DY, Puder J, Horsch A. How diet, physical activity and psychosocial well-being interact in women with gestational diabetes mellitus: an integrative review. BMC Pregnancy Childbirth. 2019;19(1).

12 Lin YZ, Hc Lee YC. Effects of maternal lifestyle factors in early pregnancy on neonatal outcomes: ya-Zhu Lin. Eur J Publ Health. 2016;26(1).

13 Patsy M, Brannon CLT. Iron supplementation during pregnancy and infancy: uncertainties and implications for research and policy. Nutr J. 2017;9(12):1327.

14 Procter SB, Campbell CG. Position of the academy of nutrition and dietetics: nutrition and lifestyle for a healthy pregnancy outcome. J Acad Nutr Diet. 2014;114(7): 1099-1103.

15 Jelsma JGM, Van Leeuwen KM, Oostdam N, et al. Beliefs, barriers, and preferences of European overweight women to adopt a healthier lifestyle in pregnancy to minimize risk of developing gestational diabetes mellitus: an explorative study. $J$ Pregnancy. 2016, 2016.

16 Soltani Hora, Debbi Smith EO. Weight, lifestyle, and health during pregnancy and beyond. J Pregnancy. 2017.

17 Zhang C, Tobias DK, Chavarro JE, et al. Adherence to healthy lifestyle and risk of gestational diabetes mellitus: prospective cohort study. BMJ. 2014;349.

18 van Dijk MR, Oostingh EC, Koster MPH, Willemsen SP, Laven JSE, SteegersTheunissen RPM. The use of the mHealth program Smarter Pregnancy in preconception care: rationale, study design and data collection of a randomized controlled trial. BMC Pregnancy Childbirth. 2017;17(1).

19 Li Tang XP. Maternal lifestyle and nutritional status in relation to pregnancy and infant health outcomes in Western China: protocol for a prospective cohort study. BMJ Open. 2019;7(6), e014874.

20 Ozlem Asci GR. Effect of lifestyle interventions of pregnant women on their dietary habits, lifestyle behaviors, and weight gain: a randomized controlled trial. $J$ Health Popul Nutr. 2016;35(7):1-9.

21 Goossens J, Beeckman D, Van Hecke A, Delbaere I, Verhaeghe S. Preconception lifestyle changes in women with planned pregnancies. Midwifery. 2018;56:112-120. 22 Marangoni F, Cetin I, Verduci E, et al. Maternal diet and nutrient requirements in pregnancy and breastfeeding. Nutrients An Italian consensus document. 2016;8.

23 Horan MK, McGowan CA, Gibney ER, Byrne J, Donnelly JM, McAuliffe FM. Maternal nutrition and glycaemic index during pregnancy impacts on offspring adiposity at 6 months of age - analysis from the ROLO randomised controlled trial. Nutrients. 2016; $8(1)$.

24 Schmidt MI, Duncan BB, Castilhos C, et al. Lifestyle INtervention for Diabetes prevention after pregnancy (LINDA-Brasil): study protocol for a multicenter randomized controlled trial. BMC Pregnancy Childbirth. 2016;16(1).

25 Rauh K, Kunath J, Rosenfeld E, Kick L, Ulm K, Hauner H. Healthy living in pregnancy: a cluster-randomized controlled trial to prevent excessive gestational weight gain - rationale and design of the Gelis study. BMC Pregnancy Childbirth 2014;14(1).

26 Naja F, Nasreddine L, Al Thani AA, et al. Study protocol: mother and infant nutritional assessment (MINA) cohort study in Qatar and Lebanon. BMC Pregnancy Childbirth. 2016;16(1). 